\title{
ORIGINAL ARTICLE \\ Maximum Mouth Opening Range in Adult Patients Presented at Dental OPD CMH, Lahore
}

\author{
MUHAMMAD SHAIRAZ SADIQ ${ }^{1}$, FAREED AHMAD², ALI ANWAAR ${ }^{3}$, M. SALMAN CHISTHY4, BILAL ABDUL QAYUM \\ MIRZA $^{5}$, SHAFA AHMED 6 \\ ${ }^{1}$ Associate Professor Department of Oral Medicine, Institute of Dentistry CMH, Lahore Medical College Lahore \\ ${ }^{2}$ Assistant Professor and Head of Department of Oral Medicine, Institute of Dentistry CMH, Lahore Medical College Lahore \\ ${ }^{3}$ Assistant Professor Department of Community and Preventive Dentistry, Institute of Dentistry CMH, Lahore Medical College Lahore \\ ${ }^{4}$ Consultant Maxillofacial Surgeon, Hafr Al-Batin Central Hospital, Saudi Arabia \\ ${ }^{5}$ Professor Department of Community and Preventive Dentistry, Institute of Dentistry CMH, Lahore Medical College Lahore \\ ${ }^{6}$ Demonstrator Department of Oral Medicine, Institute of Dentistry CMH, Lahore Medical College Lahore \\ Correspondence to Dr. Muhammad Shairaz Sadiq dr_shairaz@hotmail.com; +92 3334364364
}

\begin{abstract}
Objective: To determine the maximum mouth opening ( $\mathrm{MMO})$ in Pakistani adult population and its possible correlation with sex and age.

Design of the Study: It was a cross-sectional study.

Study Settings: This study was carried out at Outpatient Department of Dentistry Combined Military Hospital, Lahore from January 2019 to July 2019.

Material and Methods: The study involved 894 adults' patients having 463 males and 431 females patients age in the range of twenty one year to seventy years. The patients were asked maximally open their mouth and keep it open until no further opening of mouth possible. Then with the help of calibrated fiber ruler distance was measured from incisal edge of the upper incisor teeth to the incisal edge of the lower incisor teeth. To check the correlation of mouth opening with age a Pearson correlation analysis was done and significance of the test was checked by applying the independent sample T-test will be applied taking $p$ value of $\leq 0.05$ as statistically significant. A written informed consent was obtained from every patient.

Results of the Study: For males mean maximum opening of mouth was observed as $51.4 \pm 8.1 \mathrm{~mm}$ having its range 38 to 70 . Mean maximum opening of mouth for females was observed as $43.1 \pm 5.9 \mathrm{~mm}$ having age range 37 to $55 \mathrm{~mm}$. In 21 to 30 years age group the opening of mouth was $39.90 \pm 5.02 \mathrm{~mm}$ for female's patients and $40.26 \pm 5.26 \mathrm{~mm}$ for male patients. In 31 to 40 years age group the opening of mouth was $39.54 \pm 4.69 \mathrm{~mm}$ for females and for female's patients it was $40.24 \pm 4.55$ for male patients. In 41 to 50 years age group MMO was $40.24 \pm 5.02 \mathrm{~mm}$ for females and was $40.97 \pm 4.79 \mathrm{~mm}$ for males. In age 51 to 60 years age group the equivalent values for males were $41.54 \pm 5.49$ and for females $41.04 \pm 5.63 \mathrm{~mm}$. In 61 to 70 years age group the corresponding values for females and males were $40.33 \pm 5.55 \mathrm{~mm}$ and $41.25 \pm 6.04$ respectively.

Conclusion: The mean MMO for males was $51.4 \pm 8.2$ and for females was $43.1 \pm 6.7$. The opening of the mouth looks to reduce with age. The opening of mouth of females is not as much of the males in the all groups of age.

Keywords: Maximum mouth opening (MMO), Age, Sex
\end{abstract}

\section{INTRODUCTION}

Maximum mouth opening (MMO) is defined as maximum distance between incisal brink of mandibular central incisor to the incisal brink of maxillary central incisor at that time when mouth opened to its maximum possibility without pain or distance of inter incisnal and overbite ${ }^{1}$.

Although craniofacial malignancies, dental infections, myopathies and fractures in area of head and neck is caused decreased opening of mouth ${ }^{2}$. All orthodontist doing examine of oral cavity have to face different complications when opening of the mouth is very limited ${ }^{3}$.

Limitation in opening of mouth is main symptoms of various traumatic and pathological disorders. A limited opening will limit the access into the oral cavity, thus preventing a good intraoral assessment, and in dentistry particularly, making the treatment procedure of dental diseases more difficult ${ }^{4}$. Earlier detection of limited or decreased opening of mouth is compulsory for efficient approach to analyze and to choose the treatments options carefully. To evaluate the decrease opening of the mouth it

Received on 13-02-2021

Accepted on 09-06-2021 is needed to also check the parameter which constitutes normal opening of the mouth in population ${ }^{5,6}$.

Maximum íncisal opening (MIO) might be described as either as the interincisal distancě or as amended interincisal distancĕ, it is calculated by addition of the volume of vertical overlap among upperr and the lower incísors to the incísal distance. Maximum incísal opening (MIO) is stable and doesn't differ in adults; it increases along somatic growth among children?.

The normal range of mouth opening are relative to age, sex, and race, and these variables are important in the assessment and diagnosis of limited mouth opening. Researchers have shown that this measurement diverges significantly with age, ${ }^{[8]}$ gender ${ }^{[9,10]}$ and race. ${ }^{[11]}$ To the best of our knowledge, there is limited published Pakistani studies determining range of mouth opening among Pakistani adults patients. So this study was tried to calculate the maximum opening of the mouth in adult's population of Pakistan. Its early recognition is necessary for a prompt and efficient approach to a diagnosis. Nevertheless knowledge of a reliable normal range of mouth opening makes this early recognition possible. This study will served as a guide for other studies and will have 
clinical utility in diagnosis and treatment of diseases which affect the opening of mouth directly or indirectly.

\section{MATERIAL AND METHODS}

Ethical approval was obtained from the Ethical Review Board (ERB) (Reference: Case \# 389/ERC/CMH/LMC). Verbal and written consent was also obtained from the study participants. This was cross-sectional study which was carried out at Outpatient Department of Dentistry Combined Military Hospital, Lahore from January 2019 to July 2019. Total 894 adults were included in this study. Patients of both genders with ages in the range of 21-70 years were included including 463 males and 431 females. With no history of trauma and infection of maxillofacial region, all patients had normal functional teeth. Those who had a history of temporomandibular dysfunction or bruxism, dental or skeletal cross bites, maxillofacial trauma, oral malignancies, and other conditions such as microstomia, oral burn contracture that can effect mouth opening were excluded. Patients were seated comfortably on dental chair in an ūpright positíon and verbally encouraged to open their mouth to the maximum possible extent without any pain. A simple steel scale (ruler) is used for measuring the mouth opening in millimeters. A millimeter graduated scale was passively placed between the incisal edges of upper and lower central incisors and mouth opening was measured. Every 50th patient was systemically checked by one of the authors. To have diversity sample and to decrease the bias we expanded the age range to 21 years to 70 years.. Assuming the error at $2 \mathrm{~mm}$ (corresponds to $5 \%$ ). All this information was recorded in a predesigned proforma along with age and gender of the patient. Age and MMO has been described by mean $\pm S D$ while gender have been described by frequency and percentage. To see the relationship of opening of mouth with age perarson correlation analysis was applied and significance of the test was checked by applying the independent sample T-test will be applied taking $p$ value of $\leq 0.05$ as statistically significant

\section{STUDY RESULTS}

For males mean maximum opening of mouth was observed as $51.4 \pm 8.1 \mathrm{~mm}$ having its range 38 to 70 . Mean maximum opening of mouth for females was observed as $43.1 \pm 5.9$ $\mathrm{mm}$ having age range 37 to $55 \mathrm{~mm}$ as showed in table 1 .

In 21 to 30 years age group the opening of mouth was $39.90 \pm 5.02 \mathrm{~mm}$ for females patients and $40.26 \pm 5.26 \mathrm{~mm}$ for male patients. In 31 to 40 years age group the opening of mouth was $39.54 \pm 4.69 \mathrm{~mm}$ for females and for female's patients it was $40.24 \pm 4.55$ for male patients.

In 41 to 50 years age group MMO was $40.24 \pm 5.02$ $\mathrm{mm}$ for females and was $40.97 \pm 4.79 \mathrm{~mm}$ for males. In age 51 to 60 years age group the equivalent values for males were $41.54 \pm 5.49$ and for females $41.04 \pm 5.63 \mathrm{~mm}$. In 61 to 70 years age group the corresponding values for females and males were $40.33 \pm 5.55 \mathrm{~mm}$ and41.25 \pm 6.04 respectively.

Statistically significant difference was observed between maximum opening of the mouth between males and females groups with $p<0.005$. Between the age and maximum opening of the mouth a linear relationship was noted in males and females with coefficient of correlation of $-0.671,-0.867$ respectively.

Table 1: Demographic features of study cohort
\begin{tabular}{|l|l|l|}
\hline & Maximum Mouth Opening & Femalě \\
\hline & Malě & 431 \\
\hline$N$ & 463 & 45.2 \\
\hline Mean $(\mathrm{mm})$ & 52.4 & 6.6 \\
\hline SD $(\mathrm{mm})$ & 8.2 & $37-55$ \\
\hline Range $(\mathrm{mm})$ & $38-70$ & \\
\hline P-value & 0.000 (significant difference) \\
\hline
\end{tabular}

Table 2: Range of mouth opening among different age groups and gender.

\begin{tabular}{|l|l|l|l|l|}
\hline \multirow{2}{*}{ Age group } & Male & Female & \\
\cline { 2 - 5 } & Mean & $N$ & Mean & $n$ \\
\hline $21-30$ & $40.26 \pm 5.26$ & 102 & $39.90 \pm 5.02$ & 99 \\
\hline $31-40$ & $40.24 \pm 4.55$ & 98 & $39.54 \pm 4.69$ & 96 \\
\hline $41-50$ & $40.97 \pm 4.79$ & 99 & $40.24 \pm 5.02$ & 86 \\
\hline $51-60$ & $41.54 \pm 5.49$ & 87 & $41.04 \pm 5.63$ & 79 \\
\hline $61-70$ & $41.25 \pm 6.04$ & 77 & $40.33 \pm 5.55$ & 71 \\
\hline
\end{tabular}

\section{DISCUSSION}

The present study showed mean MMO is $51.4 \pm 8.2$ and $43.1 \pm 6.7$ in males and females, respectively. The range was $37-55 \mathrm{~mm}$ as showed. Which was closely related with the finding of Sohail et al. ${ }^{[12]}$ which found values as $53.6 \mathrm{~mm}$ and $51.97 \mathrm{~mm}(36.38-61.23 \mathrm{~mm})$. Whereas Qayyum et al. $^{[13]}$ also find similar findings $47.86 \mathrm{~mm}(35.84-59.66 \mathrm{~mm})$ in male and females respectively. These studies show marked difference in $\mathrm{MMO}$ among males and females whereas our study demonstrated no significant difference $(p=0.089)$. Moreover, in study by Qayyum et al, number of patients 680 with age range from 18 to 70 years; the mean value and range of maximal mouth opening was $51.97 \mathrm{~mm}$ (36.38 to $61.23 \mathrm{~mm}$ ) and for females mean value was $47.86 \mathrm{~mm}$ (35.84 to $59.76 \mathrm{~mm}$ ). However, in our study, sample size is bigger (894) with age diversity (21-70) in both males and females.

There is no significant difference in $\mathrm{MMO}$ amongst genders in different age groups of our study $(p=0.581)$. A study by Odai et al. ${ }^{[14]}$ conducted in Nigeria showed similar results and Cox et al. ${ }^{[15]}$ study in Nepal showed that females have wider mouth opening than males (female: $47.8 \mathrm{~mm}+6.8$ and male $46.8 \mathrm{~mm}+6.6)$. Moreover, other studies showed significant gender difference. The result of current study noted as maximum opening of the mouth of males patients was significantly greater than of females ( $P$ $<0.005$ ).

These results are in line with the findings of the Casanóva-Rosado et al. ${ }^{[16]}$ who evaluated the maximum opening of the mouth among adults of Mexican population. Similar findings were observed by Sohail et al. ${ }^{[12]}$ Sawair et al. ${ }^{[17]}$ Yao et al. ${ }^{[18]}$ and Gallaghe et al. ${ }^{[19]}$ who assessed $\mathrm{MMO}$ in adult subjects.

A limitation reported in our study is the purposive sampling from only one location with limited ethnicities and inference. The advantage, however, is the large sample size in comparison with other studies. To establish MMO range in Pakistani population, future studies can be guided towards an even large sample size with major ethnicities and inference. 
The reported results of the current study will served as the guide for analysis of different kind of disease about the utility of masticatory system disturbing opening of the mouth. Future research is the need of the hour to determine the underlying factors that contribute to such variations. A larger sample size from a multicenter setting should be utilized, and results should be compared between normal subjects and those with temporomandibular disorders

\section{CONCLUSION}

The mean $\mathrm{MMO}$ for males was $51.4 \pm 8.2$ and for females was $43.1 \pm 6.7$. The opening of the mouth looks to reduce with age. The opening of mouth of females is not as much of the males in the all groups of age.

\section{REFERENCES}

1. Fatima J, Kaul R, Jain P, Saha S, Halder S, Sarkar S. Clinical measurement of maximum mouth opening in children of Kolkata and its relation with different facial types. J Clin Diagn Res. 2016;10(8):ZC01-ZC05.

2. $\mathrm{Li} X Y$, Jia $\mathrm{C}$, Zhang $Z \mathrm{C}$. The normal range of maximum mouth opening and its correlation with height or weight in the young adult Chinese population. J Dent Sci. 2017;12(1):569.

3. Koruyucu M, Tabakcilar D, Seymen F, Gençay K. Maximum mouth opening in healthy children and adolescents in Istanbul. Dentistry. 2018;6(1):1-7.

4. Chen $Q$, Zhao $Y$, Shen G, Dai J. Etiology and pathogenesis of hemifacial microsomia. $J$ Dent Res. 2018;97:1297-305.

5. Al-Noaman ASH. Assessment of maximum mouth opening among students of College of Dentistry/Babylon University. Kufa J Nurs Sci. 2016;6:31-6.

6. Nagi R, Sahu S, Gahwai D, Jain S. Study on evaluation of normal range of maximum mouth opening among Indian adults using three finger index: A descriptive study. J Indian Acad Oral Med Radiol 2017;29(2):186-90.
7. Chaudhary FA, Ahmad B, Butt DQ, Hameed S, Bashir U. Normal range of maximum mouth opening in pakistani population: A cross-sectional study. Journal of International Oral Health. 2019 Nov 1;11(6):353..

8. Khare N, Patil SB, Kale SM, Sumeet J, Sonali I, Sumeet B. Normal mouth opening in an adult Indian population. $J$ Maxillofac Oral Surg. 2017;11(3):309-13.

9. Gallagher C, Gallagher V, Whelton H, Cronin M. The normal range of mouth opening in an Irish population. J Oral Rehabil. 2014;31(4):110-6.

10. Dosumu OO, Ibeabuchi NM, Arotiba JT, Arotiba GT. The relationship between maximal mouth opening, age, height and weight in Nigerians. Niger Dent J 2012;16:91-3.

11. Oginni FO, Akinyemi JO, Bamgbose BO, Famurewa BA Oginni OC, Kaura MA, et al. A pilot study of the maximum interincisal distance among adult Northern and Southern Nigerians. Niger J Basic Clin Sci. 2019;16:24-31

12. Sohail A, Amjad A. The range of inter-incisal opening among university students of Ajman, UAE. Pak Oral Dent J. 2015; 31:37-41.

13. Qayyum Z, Khitab U. Assessment of normal mouth opening in adults. Pak Oral Dent J. 2005;22(2);147-148.

14. Cox SC, Walker DM. Establishing a normal range for mouth opening: its use in screening for submucous fibrosis. $\mathrm{Br} \mathrm{J}$ Oral Maxillofac Surg. 2001; 35(3):40-9.

15. Odai ED, Ugboko VI. Estimation of maximum mouth opening among healthy adults in Benin-City, Nigeria. Niger $\mathrm{J}$ Dent Res. 2017;2:7-10

16. Casanova-Rosado JF, Medina-Solís CE, Casanova-Rosado AJ, Vallejos-Sánchez AA, Patiño-Marín N, Maupomé G, Gómez-Gómez V. Clinical characterization of mouth opening among Mexican adolescents and young adults. J Dent Sci. 2012;7:81-4.

17. Sawair FA, Hassoneh YM, Al-Zawawi BM, Baqain ZH. Maximum mouth opening. Associated factors and dental significance. Saudi Med J. 2010;31(4):369-73.

18. Yao $\mathrm{KT}$, Lin $\mathrm{CC}$, Hung $\mathrm{CH}$. Maximum mouth opening of ethnic Chinese in Taiwan. J Dent Sci. 2013;4:40-4

19. Gallagher C, Gallagher V, Whelton H, Cronin M. The normal range of mouth opening in an Irish population. J Oral Rehabil. 2010;31(2):110-6. 